\title{
Criterios básicos de las bases de datos documentales en las empresas televisivas sobre representación del contenido
}

\author{
Jorge Caldera Serrano
}

Facultad de Biblioteconomía y Documentación

Universidad de Extremadura

\subsection{Resumen}

Se enumeran y describen los campos repetidos en las diferentes bases de datos donde se plasma el análisis formal y de contenido de la documentación periodística audiovisual en el marco de las televisiones estatales. Consideramos estos campos repetidos como indispensables para una correcta gestión de archivos audiovisuales mostrando así unas directrices para la puesta en marcha de archivos televisivos para empresas audiovisuales locales. (Autor)

Palabras claves: Analisis de contenido. Documentación audiovisual. Archivos de televisión. Bases de datos.

\subsection{Abstract}

The fields repeated in the different data bases are enumerated and described where the formal analysis is shaped and of content of the audio-visual journalistic documentation in the frame of the state televisions. We considered these fields repeated like indispensable for a correct management of audio-visual archives showing therefore directives for the beginning of televising archives for local audio-visual companies. (Author)

Keywords: Content analysis. Audiovisual documentation. Archives of television. Database.

\section{Introducción a los archivos audiovisuales en televisión}

La televisión se nos presenta hoy como el medio de información con mayor seguimiento por parte de nuestra sociedad. Para una correcta gestión, al igual que para abaratar los costes de producción, la totalidad de las televisiones estatales y autonómicas —e incluso algunas locales — cuentan con archivos de gestión para reutilizar y conservar la información audiovisual generada por la empresa o adquirida por diferentes medios. 
La correcta representación del contenido es básica para la posterior recuperación de las imágenes contenidas en estos archivos audiovisuales, por lo que son muchos los esfuerzos realizados para que esta representación del contenido sea lo más efectiva posible.

Para ello, la totalidad de las televisiones cuentan con personal especializado en la gestión y explotación de estos archivos que se dedica a crear bases de datos ad hoc para estos centros; aunque suelen dejarse de lado recomendaciones realizadas por diferentes organismos supranacionales.

No obstante existen criterios que se repiten en las diferentes bases de datos audiovisuales y que son observados como básicas para la gestión de los archivos. Por ello, analizaremos en el presente artículo estos criterios, que se repiten en la gestión de estos archivos en sus diferentes bases de datos, sistematizando y esquematizando estos bancos de datos donde se conserva el material audiovisual de estas televisiones.

Recordamos que la misión de estos archivos es el control de la producción propia y del material adquirido para que pueda ser reutilizada, abaratando así los costes de producción los cuales se disparan al tener que enviar equipos completos a grabar imágenes atemporales. No tienen sentido estos archivos sino es para ofrecer estas imágenes a los usuarios de la empresa: los/as periodistas.

\section{Características del archivo de televisión}

Vamos a señalar una serie de características y peculiaridades que definen y distinguen a los archivos audiovisuales de televisión:

- Falta de normalización del tratamiento, pues hay una inexistencia de criterios o normativas de gestión del material audiovisual de las empresas televisivas por parte de entidades u organismos supranacionales dedicados directamente al estudio de la imagen en movimiento como la Federación Internacional de Archivos de Televisión (FIAT / IFTA http://nbr.no/fiat/fiat.html) con recomendaciones en su publicación Panorama de los Archivos Audiovisuales (1), el Consejo Internacional del Cine y de la Televisión (CICT), Internacional Council of Archives (ICA) y la Federación Internacional de Archivos Fílmicos (FIAF http://www.cinema.ucla.edu/fiaf). Otro organismo de gran importancia en el estudio y la investigación es el Instituto Nacional de lo Audiovisual de Francia (INA - http://www. ina.fr/index 2.html) y en menor medida las organizaciones internacionales UNESCO (http://www.unesco.org) y el Consejo de Europa (http://www.coe.fr/index.asp).

- Otra característica de la información depositada en los archivos de televisión, por ser igualmente típica de la información periodística, sería el enci-

Scire. $6: 1$ (en.-jun. 2000) 75-95. 
clopedismo, ya que en estos archivos podremos encontrar información de las materias más variadas.

- Igualmente podríamos hablar como otra característica importante de la información periodística televisiva de la universalidad tanto en el origen de las imágenes como en las fuentes utilizadas para adquirir el material audiovisual. La despersonalización (Agirreazaldegi, 1997) de la información hace en muchos casos un ejercicio altamente complicado e intuitivo el reconocimiento de personajes, lugares y temas.

- Característica igualmente importante desde nuestro punto de vista es la superficialidad (Sanabria, 1994) de la información periodística de actualidad.

- Otro aspecto primordial y relevante, desde el punto de vista del tratamiento documental, es la redundancia. Este problema en los archivos de televisión, que se traduce en muchas imágenes con idénticas connotaciones, se soluciona con una selección clara y precisa para no repetir así recursos en el archivo. Es evidente que la información televisiva está altamente ideologizada (2) ya que todas las empresas audiovisuales nos ofrecen la información aliándose a un posicionamiento político, perdiendo por tanto la objetividad - lo que puede denotar una falta de ética o código deontológico (Soria, 1997) — que se les solicita a los medios de comunicación (Ferres, 1996). Es importante también en los archivos de televisión la puesta al día de las imágenes y personajes ya que esta información tiene escasa duración vital —obsolescencia de la información.

- Otras características propias del archivo audiovisual vienen marcadas por su propio origen funcional, al estar estos archivos creados para conservar y reutilizar los productos televisivos realizados por estas televisiones en su actividad diaria. Otra peculiaridad es la diversidad en su tipología documental, lo que se traduce en problemas de almacenamiento, necesidad de reproductores con los que no siempre se cuenta y una evolución rápida de los soportes, con la consiguiente necesidad de nuevos magnetoscopios. No podemos hablar de características propias de un archivo sino tenemos en cuenta el factor humano al que va destinado dicho tratamiento audiovisual, así como la recuperación de la información: el usuario, principio y fin de estos servicios de documentación. Las prisas y la necesidad de pertinencia son cuestiones que hacen necesaria la figura del profesional intermediario para la solución de estas necesidades informativas. La unidad documental en estos servicios aún no está lo suficientemente estudiada y analizada. Tan sólo señalaremos que la unidad documental tal y como la entendemos ahora en estos servicios no tiene cabida en los archivos audiovisuales, ya que 
la unidad de tratamiento y difusión variarán según las características de las necesidades reales del usuario.

- Otra característica importante de estos archivos es la necesidad de variar los criterios del tratamiento documental a la vista del cambio en las modas informativas de solicitud de información de usuario. Es decir, el análisis deberá mostrar las necesidades reales del usuario y no un análisis ideal "a priori" acordado por el personal de documentación.

La utilización que se le puede dar a estos archivos es de lo más variada. Destacaremos entre otros usos la labor de verificación de datos. Aunque este fin es propio de los departamentos de documentación escrita de las diferentes televisiones, también el archivo audiovisual podrá ser utilizado para este fin. Pero, sin duda alguna, la utilidad prioritaria de estos archivos es la reutilización de recursos de imagen de personas, materias y lugares. Afirmamos como incuestionable el por qué de la existencia de los archivos de televisión que tiene como fin principal la reutilización de material, satisfaciendo así las necesidades informativas de los periodistas. Pero, de igual manera, en los archivos de televisión se conserva información de incalculable valor para la Humanidad. Es por ello que conservar material de valor (Hanford, 1996, p.125-128) sea otro factor importante a la hora de hablar de las funciones de estos centros.

\section{La representación del contenido en archivos de televisión}

Al igual que en cualquier unidad de información, la información audiovisual televisiva sufre una serie de alteraciones para transformar las imágenes y el sonido que integra la imagen audiovisual en un registro documental susceptible de ser recuperado para una posterior reutilización.

La entrada de la información audiovisual en las empresas televisivas tiene diferentes procedencias que el departamento ha de conocer para su posterior control. Alguna de éstas fuentes pueden ser ser: las cámaras de la empresa audiovisual, centro territoriales, corresponsalías, enviados especiales, agencias de noticias de carácter internacional, agencias nacionales, el propio archivo para los montajes realizados con fragmentos de imágenes extraídas del material analizado por el documentalista, etc.

Durante el proceso de selección los analistas decidirán la selección o borrado de las imágenes contenidas en los videos cassette atendiendo a una serie de factores (3). El contacto entre los analistas que estudian un mismo campo temático es continuo y necesario para aclarar, cambiar y evolucionar los diferentes criterios de selección, los cuales no han sido establecidos casi nunca, por la empresa sino que será el personal de los departamentos de análisis audiovisual 
quién ha de determinar la necesidad de analizar y conservar para la potencial reutilización de este material en el archivo.

Es un principio totalmente aceptado el análisis y conservación de todo lo emitido por la empresa televisiva. Las emisiones tanto en programas como en informativos se conservarán siendo analizados en su totalidad. Todos los brutos de rodaje o aquél material que llegue por intercambio deberán ser analizados y conservados analizando si dicho material es relevante para el archivo, teniendo en cuenta la repetición de las imágenes en el fondo del centro audiovisual, si es necesario para la actuación del archivo, etc.

El tratamiento de la información audiovisual es llevado a cabo en una serie de etapas como son el visionado del material, el análisis cronológico o minutado y por último la indización. Todo el material que entra en los diferentes archivos de televisión será visionado en su totalidad para determinar su selección. Una vez decidido su valor, se realizará la descripción de los planos en lo que se denomina minutado o análisis cronológico. En último lugar, y a la vista del análisis cronológico, se extraerán los términos de indización de personas, lugares y temas.

Todo este análisis quedará plasmado en una serie de campos en la base de datos; campos que vamos a enumerar y que se repiten en los bancos de datos de las empresas audiovisuales televisivas. Los campos que se repiten en las diferentes bases de datos son (Corral, 1989):

- Campos onomásticos

- Campos geográficos

- Campos temáticos

- Campos cronológicos

- Campos de localización

- Campos de control

- Campo de contenido

\subsection{Campos onomásticos}

Existen una serie de campos onomásticos que se repiten en las diferentes bases de datos y son, a saber, los campos de personas físicas y jurídicas referenciadas en las imágenes, al igual que otro campo dónde se incluyen las personas físicas y jurídicas visionadas en las imágenes. Es decir, se diferencia entre lo que se ve y de quién se habla. Mientras el primer campo señalado nos muestra sobre qué personaje/s se desarrolla el tema, en el segundo de ellos señalamos los personajes cuyas imágenes se podrán reutilizar en el futuro.

Otros campos onomásticos repetidos son aquellos en los que se indica la realización, producción y cuadro técnico que han producido la noticia, así como la 
dirección e interpretación de piezas artísticas — literarias, teatrales, musicales, etc.- visionadas o referencias en el producto televisivo o en los brutos de rodaje.

Las reglas para la elaboración de puntos de acceso de personas son elaboradas por cada departamento de documentación y creadas "ad hoc", una vez analizadas las necesidades propias del servicio. TVE (http://www.rtve.es), por ser la primera televisión en España, es el modelo a seguir por parte de otras televisiones estatales y autonómicas (4). Este servicio adapta las reglas de catalogación a las necesidades del servicio de documentación audiovisual, teniendo como premisa identificar a estos personajes por su nombre más conocido.

\title{
3.2. Campos geográficos
}

Los campos geográficos repetidos en las diferentes bases de datos de las empresas televisivas no son tan universales como los anteriores. Todas estas bases de datos cuentan con un campo donde se muestran las zonas geográficas o países sobre los que influye un acontecimiento o noticia. Una cumbre entre los jefes de estado de España y Portugal tendrá ambos países en dicho campo, pero la inclusión en este campo no significa que existan imágenes de estos países en la información ya que será en otro campo dónde se deberá indicar la existencia de imágenes de un determinado lugar.

Otro campo geográfico nos ubica la noticia en una localidad o país en el caso de desconocer la ciudad. En el campo dicho —denominado de diferentes maneras - se señala la ciudad en la cual se produce la noticia — varias ciudades si fuera necesario - , aunqueno se muestren imágenes de ellas..

Aún podemos hacer patente la existencia de un campo geográfico en el que se nos indica por ejemplo, la ciudad de la cual se nos ofrecen recursos visuales que pueden ser reutilizados para futuras noticias. Se señalará la ciudad si se nos muestran imágenes sin especificar una parte concreta dentro de la misma. Igualmente en este campo si las imágenes son mucho más concretas que el ejemplo anterior, se deberá indicar la ciudad, la descripción de la imagen y los efectos atmosféricos destacables (Figura 1).

\author{
Ejemplo: \\ -Madrid - Palacio de La Moncloa (Exterior) (Lluvia)
}

Fig. 1

Scire. 6: 1 (en.-jun. 2000) 75-95. 
Existen herramientas más o menos desarrolladas para la descripción de zonas geográficas, países, localidades, etc. Estos tesauros elaborados por el propio personal del servicio y con un mantenimiento continuo son herramientas ágiles, útiles y muy desarrolladas para estos servicios de documentación.

\subsection{Campos temáticos}

Al igual que en los campos onomásticos y geográficos existe una distinción clara entre lo visionado y lo referenciado, en los campos temáticos se utiliza la misma filosofía contando siempre con un campo tema y otro plano tema.

En el campo tema se indicará la temática de la noticia con independencia de las imágenes, es decir, nos clasifica el concepto que nos muestra la noticia una vez montada y editada, no la relación real entre imagen y sonido, ya que ésta no siempre existe. Por lo tanto, este campo de tema analizará la banda sonido teniendo en cuenta la locución, sonido ambiente, declaraciones, etc. - tanto como la banda imagen.

En los campos de descripción temática audiovisual se plasman la temática de las imágenes contenidas en la noticia, plano a plano, ya que una noticia televisiva está organizada por fragmentos de imágenes que no siempre tiene una relación temática entre ellas, al igual que tampoco ha de existir relación con la banda sonido. Por lo tanto, mientras que el campo "tema" analizaba la banda sonido, el campo "plano tema" lo olvida, centrando su representación en la banda imagen.

Existe un campo en la base de datos de TVE y Antena 3 TV (http://www.antena3tv.es) denominado "Identificador", el cual es una forma de aglutinar, por medio de este calificador, a una serie de noticias generadas a partir de un mismo hecho, un mismo personaje, etc. Un ejemplo de posible calificador podría ser "Expo 92", por lo que señalando este identificador a la hora de la búsqueda tendríamos todos los documentos que están relacionados de manera directa o indirecta con dicha temática. Otro ejemplo de la utilidad de dicho campo temático sería el "Caso Roldan" ya que así se podría seguir por medio de esta clave todo el proceso penal que ha sufrido éste persona, desde los primeros momentos en los que se descubren los hechos susceptibles de investigación, al desarrollo de los juicios, pasando por las salidas de la cárcel para visitar los juzgados.

Las herramientas documentales existentes para plasmar dicha información en la base de datos son listas de encabezamientos de materias y tesauros de diferentes temáticas. Estas herramientas son creadas "ad hoc" por el personal de documentación de estas empresas, al igual que el mantenimiento de las mismas. Estas herramientas utilizan términos muy amplios de tal manera que es necesaria la inclusión de gran cantidad de descriptores para especificar la temática de los documentos.

Scire. 6:1 (en.-jun. 2000) 75-95. 


\subsection{Campos cronológicos}

Se repiten una serie de campos cronológicos en estas bases de datos. El primero es el campo en el cual se especifica la fecha en la cual se ha producido la noticia. Igualmente, un segundo mostrará la fecha de emisión de dichas imágenes, ya que no tienen por qué coincidir ambas fechas.

Respecto a la fecha en la que se ha producido la noticia, es necesario indicar que no siempre será una fecha determinada, un día concreto, por lo que tendremos que tener en cuenta que la grabación de las imágenes ha podido ser realizada en días diferentes. Para controlar este aspecto existen sendos campos en los que se especifica la fecha de inicio y la fecha final de la grabación de las imágenes. En este caso no será necesario confeccionar el campo de fecha de noticia ,ya que, entre otras cuestiones, sería incorrecto.

Sobre la fecha de emisión es necesario señalar que, según las televisiones y dependiendo de sí la base de datos analiza programas o informativos, existe un campo en el que se mostrará no solo la primera fecha de emisión sino también todas las repeticiones del programa que se haya producido a lo largo del tiempo.

\subsection{Campos de localización y características técnicas}

A continuación, indicamos otros campos repetidos, a los que por ser mucho menos interesantes para el análisis de contenido de la documentación audiovisual les dedicaremos menos atención.

Existen una serie de campos que nos señalan la localización física de la cinta en el fondo documental del archivo (tejuelo), al igual que otros campos que nos indican dónde encontrar las imágenes dentro de la cinta — datos de localización.

Otros campos nos muestran las características técnicas del vídeo, como puede ser el soporte, el formato, la existencia de insertos en blanco en negro, la carencia o existencia de sonido natural, etc. En algunos casos, es importante también para la descripción física de la información el campo duración, por el cual conocemos el tiempo real de la información contenida en el soporte.

\subsection{Otros campos repetidos}

Un campo muy repetido es el de control del analista para control de la producción, selección y borrados realizados por cada uno de los trabajadores del servicio.

Otro campo relevante en la documentación audiovisual es aquel en el cual se especifica los derechos a los que está sujeta la información contenida en el vídeo. En este campo se indicará quién detenta los derechos — especificando nombre y forma de contacto con esta persona física o con la entidad- y cuáles son éstos: reutilización, alcance, explotación y venta, etc. 
También podemos indicar la existencia de un campo de notas donde se incluirán todos aquellos datos que no tienen cabida en el resto de campos, como pudiera ser la existencia de una parte de imágenes defectuosas, la falta del Time Code - Código de Tiempo- grabado en el soporte, relación con otros documentos del archivo, etc.

\subsection{Campo Contenido}

Otro campo repetido y básico en estos servicios es el campo de contenido o planos (5) en el cual se desarrollan las imágenes contenidas en las imágenes.

Existe un campo real mente importante al cual no nos hemos referido, que es el campo título. El título es un titular propuesto por el propio analista una vez visionado el documento audiovisual y tras conocer o descifrar la temática de la información televisiva. Por lo tanto, este campo título estará sujeto a la subjetividad del analista al igual que ocurre en el caso de la descripción de las imágenes. Este título debe ser claro, conciso y preciso, pero no telegráfico, explicando la temática de lo visionado (Fig.2). Este campo de título vendrá asignado por la empresa en el caso de que el producto sea un programa con título propio (cosa que no ocurre con las noticias de informativos).

Volviendo al campo de descripción de planos, podemos señalar que es un ejercicio, a veces nada fácil, de reconocimiento de personas, lugares y temas, partiendo de la experiencia y los conocimientos del analista. La elaboración de este campo de contenido aún está por estudiar e investigar desde el punto de vista de la elaboración, ya que es necesario formular una metodología de lectura de imágenes. Desde el punto de vista formal, señalamos que en un primer momento se habrá de señalar la data cronológica, es decir, la hora, minuto y segundo en las cuales comienza las imágenes descritas dentro de la cinta. Con posterioridad señalaremos el plano (si es significativo) y finalmente describiremos la acción.

\section{Ejemplo:}

00:04:32 PG José María Aznar, presidente del gobierno español, saludando al dirigente cubano Fidel Castro en el exterior del Palacio de La Moncloa. 
Los problemas para la descripción de estas imágenes son muchos. El primero ser capaz de mostrar con palabras una acción visual teniendo en cuenta las necesidades del usuario. Otra cuestión mucho más fácil de solucionar es el conocimiento de planos, encuadres, efectos de iluminación, movimientos de cámaras, etc. Es conveniente que el analista documentalista conozca no solo estas cuestiones fotográficas y/o cinematográficas sino que también debería conocer las etapas de producción de la noticia informativa, y ser capaz de identificar las características de los productos audiovisuales televisivos, lo cual ayudaría, en gran manera, a la mejora del análisis.

Mostramos a continuación un ejemplo de documento audiovisual de los Servicios Informativos de Televisión Española (Fig.3)

Título: Cumbre de Bill Clinton y Boris Yeltsin con motivo de la celebración del 50 aniversario de la ONU. Ataque de risa de Clinton en la conferencia de prensa conjunta

21:20:03 Entradilla Corresponsal en Estados Unidos

21:20:15 Clinton y Yeltsin sentados en exterior de antigua casa del presidente Roosevelt en Manhattan dialogando

21:20:23 P.G. Ambos se levantan y caminan hacia el interior de la casa, rodeados de escolta

21:20:40 P.A. Clinton y Yeltsin posando en interior de mansión

21:20:51 Estudio

21:20:56 R.P. de Yeltsin y Clinton. Carcajadas de Clinton por declaraciones de Yeltsin sobre los periodistas

21:21:32 Fin

Figura 3

Scire. $6: 1$ (en.-jun. 2000) 75-95. 
Otros campos de representación del contenido del visionado anterior son los siguientes:

- Plano Personas: CLINTON, Bill * YELTSIN, Boris

- Personas: ROOSEVELT

- Tema: Periodismo - Periodista * Política internacional

- Plano Tema: Dirigentes políticos * Anécdotas personales * Actos oficiales - cumbre

- Ambito: Federación Rusa * Estados Unidos

- Lugar: Manhattan

Incluimos igualmente, y a modo de ejemplo, un documento del programa informativo Informe Semanal de Televisión Española (TVE). Los datos de control y analista junto con los datos de descripción de las cintas no han sido señalados por carecer de interés para la finalidad de este ejemplo y además puede ir contra la privacidad del analista documentalista

- Titulo:Invierno de los sin techo, el (mendigos durante el invierno)

- Duración: 00:11:57 (sólo la emisión)

- Fecha emisión:19970111

- Emisión:1cad, semanal, sa, 21:30 H.

- Serie:Informe Semanal (0549)

- Forma: Reportaje

- Nota: Originales tratados en documento independiente con el campo fuente cumplimentado con el titulo del reportaje "El invierno de los sin techo"

- Dirección: Magro Santana; Baltasar (dir)* Falcet, José Manuel (rea)

- Cuadro técnico: Artero Rueda; Manuel (gui)

- Lugar:Madrid * León

- Plano Tema:Personas y grupos sociales - marginados* Mendicidad * Beneficencia - asistentes sociales * Beneficencia centros 
- Tema: Personas y grupos sociales - marginados * Mendicidad * Meteorología - frío * Meteorología - Invierno

- Contenido: Reportaje sobre uno de los colectivos más desfavorecidos de nuestra sociedad, los indigentes, a raíz del temporal de frío que ha azotado al país

00:52:05 Noche: indigentes durmiendo en la calle y en el metro. Título.

00:52:47 Testimonio de un indigente joven sobre lo duro que es vivir en la calle.

00:53:12 Colas para entrar en un albergue social mientras nieva por la noche. Un sin techo dice que tiene el estomago destrozado. Indigentes en el interior del albergue.

00:53:50 Noche: calle nevada desde vehículo en marcha, dos asistentes sociales de la unidad móvil de emergencias de Madrid hacen el recorrido habitual buscando indigentes para llevarlos al refugio, hablan con una mujer tumbada en la calle que les responde inconexamente.

00:54:22 Rocío Alvarez, asistente social del ayuntamiento de Madrid, comenta que esta mujer lleva desde 1990 en la calle y no colabora.

00:55:15 Testimonio de un indigente señalando que el albergue parece un psiquiátrico.

00:55:39 Indigentes, con actitud de profundo cansancio y dejadez. Reponiendo fuerzas en el albergue.

00:56:00 Una mujer dice que su familia ha intentado ayudarla, pero ella lo ha dejado escapar.

00:56:23 Mendigos durmiendo por la noche en la calle y en el metro arropados con mantas.

00:57:05 Isidoro, un indigente desdentado, habla de las excelencias de vivir en la calle desde su colchón en el metro.

00:57:29 Indigentes en la calle, cola ante un comedor de caridad. 00:57:58 Plaza de León nevada, calles del casco histórico (noche) 
00:58:12 El reportero entrevista a una mujer joven, con las facultades mentales alteradas, que se encuentra en plena noche sentada en un banco a la intemperie.

00:59:28 Conversación inconexa entre la mujer y su compañero borracho, planos ralentizados. Él declara su amor hacia ella, borracho.

01:00:20 Los dos sentados en un banco de plaza nevada solitaria conversan, cantan.

01:01:02 Nieve en la estación de tren de León, un carrilano (aquel que sigue las vías del tren buscando nuevos albergues) en la estación.

01:01:25 Indigente joven vendiendo la revista de los sin techo "Transeuntes" en una calle de León. Comenta que la soledad es peor que el frío.

01:02:09 La cámara recorre una calle de Madrid por la noche en la que duermen varios sin techo.

01:02:30 Luis Peñafiel, ex legionario, habla desde su esquina en la calle de la gente que, a diferencia de él, no es feliz.

01:03:18 Tráfico, gente por la calle, indigentes en la calle, rótulos de salida.

01:04:02 Fin.

Mostramos el campo de descripción de planos de un registro del archivo audiovisual de Antena 3 TV (6)

- Título:Diputados y ministros entrando y saliendo del congreso de los diputados

- Descripción de planos:

00:01:25 El Rey Juan Carlos I recibe a Felix Pons, Presidente del Congreso de los Diputados, con motivo de la constitución del Congreso (26 de junio de 1993).

00:01:05 PM Don Juan Carlos I saludando a Felix Pons. 
00:02:03 Constitución del Congreso de los diputados tras las elecciones generales de 1993, entradas y salidas de diputados y pasillos del congreso (29 de junio de 1993).

00:02:03 DP Jordi Sole Tura entrando en el edificio.

00:02:12 DP Vicente Albero entrando en el edificio.

00:02:17 DP Carlos Solchaga junto a Eduardo Martín Toval entrando en el edificio.

00:02:37 DP Federico Trillo andando por los pasillos del Congreso de los Diputados.

00:02:45 DP José María Aznar andando por los pasillos.

00:02:53 PC Declaraciones de Julio Anguita quejándose de la distribución final de la mesa del Congreso y del "cambio" de Felipe González.

00:04:10 DP José Borrell hablando con otros compañeros.

00:04:18 PC Declaración de Jon Idígoras antes de obtener su acreditación como diputado, sobre ETA "no nos podemos permitir el frivolizar sobre el enfrentamiento Euskadi-Estado".

00:08:39 DP Jon Idígoras andando por una sala del Congreso y leyendo el periódico.

00:09:39 PC Francisco Alvarez Cascos hablando con otros diputados.

00:09:50 PM Felipe González junto a Carlos Solchaga andando por los pasillos del Congreso.

00:10:08 PM Baltasar Garzón hablando con Tomás de la Quadra en los pasillos.

00:10:30 PM Alfredo Pérez Rubalcaba hablando con periodistas

00:10:53 PM Felipe González entrando junto a Baltasar Garzón por la puerta de acceso.

00:11:00 PC Declaraciones de Felipe González sobre acuerdos o pactos electorales con otros partidos.

Incluimos un documento de Antena 3 TV con la descripción de planos y los campos de descriptores: 
- Area de control

- Analista

- Fecha de entrada: 25/03/92

- Tipo de grabación: original bruto

- Temporalidad cinta: definitiva

- Area de título:

- Título: el rastro de Madrid

- Area de producción:

- Fecha:1990

- Propiedad: Propia

- Centro: Madrid

- Derechos: No

- Area de descriptores:

- Planos:

00:01:00 Mercado. El rastro de Madrid.

00:01:05 DP vendedores desmontando y recogiendo los puestos.

00:01:55 PG Vendedores y compradores con ropa de verano, en un puesto de bisutería.

00:02:17 DP mujer pelirroja.

00:03:04 PG puesto de El Rastro.

00:03:13 DP Puesto de objeto de vidrio: copas, botellas, vasos...

00:03:23 PG puesto de gafas de sol.

00:03:27 PG puesto de bisutería con compradores y vendedores.

00:03:36 DP puesto de ropa.

00:03:58 PG puesto de gafas de sol. 
00:04:19 PG El Rastro a última hora, con pocas personas por la calle.

00:04:52 DP puestos de insignias y escudos.

00:05:34 PG puestos de objetos de vidrio.

00:05:56 DP puesto de juguetes de madera.

00:06:29 DP Librillos de papel de fumar.

00:06:59 PP Cara de mujer morena.

00:07:03 DP Hombre joven gordo con camiseta de tirantes echándose agua por la cabeza.

00:09:53 DP Estatua de Eloy Gonzalo en la Plaza de Cascorro de Madrid.

.......

- Resumen: Grabación en bruto del mercado de El Rastro de Madrid, con imágenes de puestos, vendedores recogiendo y barrenderos limpiando las calles una vez finalizada la venta en el mercado.

- Descriptores temáticos Imagen: Cara * agua * vendedores ambulantes $*$ clientes $*$ calles $*$ mercadillos $*$ venta - ambulante - comerciantes $*$ peatones $*$ estatuas $*$ barrenderos $*$ plazasmonumentos * limpieza - urbana * basura

- Otros campos de descriptores:

Descriptores temáticos no imagen.

- Persona imagen

- Persona no imagen

- Entidad imagen

- Entidad no imagen

- Descriptores geográficos

- Lugar: Madrid

- Planos de lugares: Madrid: Plaza de Cascorro * Madrid: El Rastro

- Otras áreas de análisis: 
- Area de Fecha

- Area de Emisión

- Area de descripción física

\section{Conclusiones}

La descripción del contenido en los archivos de televisión es un ejercicio cotidiano en las empresas televisivas. Sin embargo, aún no se han planteado la necesidad de optimizar el tratamiento de esta información desde el punto de vista documental. Un trabajo detallado y en las condiciones que se está realizando actualmente en estos servicios hace necesaria una plantilla amplia y especializada, lo cual nos se da en la práctica en estas unidades.

Las necesidades reales del usuario y las características del análisis no están siempre en sintonía, por lo que la mayor parte de los esfuerzos futuros deberán realizarse en este sentido. Es decir, es necesario conocer las necesidades de los usuarios para mejorar el análisis y la descripción de la información contenida en las imágenes, evitando datos irrelevantes y ofreciendo al periodista los elementos con los que ellos han compuesto la información televisiva (Paradigma de Lasswell), por lo que estamos obligados a sentar las bases de una lectura de imagen teniendo como punto de partido al usuario y no las posibilidades documentales.

Falta de normalización a nivel internacional, falta de cultura documental en las empresas audiovisuales, escasa valoración del personal de estos servicios, miedo al cambio y evolución de herramientas documentales, etc., son problemas que se deberán ir solucionando en un futuro próximo, lo cual será favorecido por el desarrollo de la investigación documental en este ámbito y por el aumento de el número de servicios $\mathrm{y}$, por tanto, de los profesionales que trabajarán en estos servicios.

\section{Notas}

(1) Las principales recomendaciones de la FIAT / IFTAestán recogidas en su página web y también en Panorama... (1986).

(2) Jaime Barroso García (Barroso, 1992, p.86) habla de manipulación a favor del poder político.

(3) Paloma Hidalgo señala la diferencia entre "selección y expurgo" ya que dice: "la primera se aplica a priori para decidir qué documentos se incorporan temporal o definitivamente, el expurgo se aplica a posteriori para eliminar los que se habían incorporado al fondo..." (Hidalgo, 1999, p. 483). 
(4) Se analiza la Base de Datos de los Servicios Informativos de TVE en Caldera (1999, p. 365-371)

(5) En TVE el campo de análisis cronológico o minutado es denominado con el nombre de campo de "contenido" mientras que en Antena 3 TV se nos muestra con el nombre de "planos".

(6) Ejemplos sacados de material del curso "Documentación en medios de comunicación” organizado por la Asociación de Titulados Universitarios en Documentación y Biblioteconomía de Salamanca (ADAB-Salamanca) en noviembre de 1995 e impartido por Lucía Mendoza, documentalista de Antena 3 TV.

\section{Bibliografía}

Agirreazaldegi Berriozabal, Teresa (1997). El uso de la documentación audiovisual en los programas informativos diarios de televisión. País Vasco : Servicio Editorial de la Universidad, 1997.

Barroso García, Jaime (1992). Proceso de la información de actualidad en televisión. Madrid : Instituto Oficial de Radio y Televisión , 1992.

Caldera Serrano, Jorge (1999). Representación del contenido de imagen en movimiento. Organización del Conocimiento en Sistemas de Información y Documentación. 4 (1999).

Corral Baciero,Manuel (1989). La documentación audiovisual en programas informativos. Madrid : Instituto Oficial de Radio Televisión, 1989.

Ferrés i Prats, Joan (1996). Televisión subliminal : socialización mediante comunicaciones inadvertidas. Barcelona ; Buenos Aires ; México : Paidós, 1996.

Hanford, Anne (1996). Normas recomendadas y procedimientos para seleccionar material de televisión. // Panorama de los Archivos Audiovisuales : contribución a la puesta al día de las técnicas de archivo internacionales. Madrid : RTVE, 1996.

Hidalgo Goyanes, Paloma (1999). Documentación audiovisual. // Introducción a la documentación informativa y periodística. Sevilla: MAD, 1999.

Panorama de los archivos audiovisuales: contribución a la puesta al día de las técnicas de archivo internacionales. Madrid: RTVE, 1.986.

Sanabria, Francisco (1994). Información audiovisual: teoría y técnica de la información radiofónica y televisiva. Barcelona : Bosch, 1994.

Soria, Carlos (1997). El laberinto informativo: una salida ética. Pamplona : Eunsa, 1997. 